\title{
Chemical composition and antibacterial activity of Clinopodium nepeta subsp. glandulosum (Req.) Govaerts essential oil
}

\author{
Gözde ÖZTÜRK ${ }^{1, *}$, (D) Gülderen YILMAZ² (iD) Gülnur EKŞi² and (D) Betül DEMIRCi ${ }^{1}$ \\ ${ }^{1}$ Department of Pharmacognosy, Faculty of Pharmacy, Anadolu University, 26470, Eskişehir, TURKEY \\ ${ }^{2}$ Department of Pharmaceutical Botany, Faculty of Pharmacy, Ankara University, 06100, Ankara, TURKEY
}

*Corresponding author. Email: g.ozturkua@gmail.com

Submitted: 21.06.2021; Accepted: 06.09.2021

\begin{abstract}
Clinopodium nepeta subsp. glandulosum (Req.) Govaerts is a natural perennial grass belonging to the Lamiaceae family, growing spontaneously on the Mediterranean coast. It is locally known as "kedi fesleğeni" in Turkey. This aromatic plant is used as a mint-like spice in food preparations and in the composition of some recipes during religious feasts. In folk medicine, it is used as stimulant, antiseptic and antispasmodic. Aerial parts of C. nepeta subsp. glandulosum were collected from Bilecik in July 2017, and was air dried. The essential oil was isolated by hydrodistillation using a Clevenger-type apparatus and the composition of the essential oil was simultaneously analysed by GC-FID and GC-MS. Piperitenone oxide (47.8\%), limonene (18.6\%) and piperitone oxide II (13.6\%) were found as major components. Antibacterial activity of the essential oil was tested against Escherichia coli NRRLB-3008, Pseudomonas aeruginosa ATCC 27853, Salmonella typhimurium ATCC 13311, Bacillus cereus NRRL-B3711 and Streptococcus sanguinis ATCC 10556 were used by broth microdilution method. Ciprofloxacin was used as control and Minimal Inhibitory Concentrations (MIC) were determined. The highest activity was found against $S$. typhimurium $(1250 \mu \mathrm{g} / \mathrm{mL})$. The essential oil is more effective against $B$. cereus $(2500 \mu \mathrm{g} / \mathrm{mL})$ and S. sanguinis $(2500 \mu \mathrm{g} / \mathrm{mL})$. The lowest activities were determined against $E$. coli $(5000 \mu \mathrm{g} / \mathrm{mL})$ and $P$. aeruginosa $(10000 \mu \mathrm{g} / \mathrm{mL})$.
\end{abstract}

Keywords: Lamiaceae, Clinopodium nepeta subsp. glandulosum, essential oil, chemical composition, antibacterial activity

\section{Introduction}

The genus Clinopodium (Lamiaceae) is represented by 39 taxa (Govaerts, 1999, Conforti et al., 2012). Clinopodium species are used in folk medicine like mints, mainly as stimulant, digestive, tonic, antiseptic (Baytop, 1999). Clinopodium nepeta subsp. glandulosum (Req.) Govaerts (syn. Calamintha nepeta subsp. glandulosa) is a perennial aromatic plant widespread in the Mediterranean region. C. nepeta occurs in Southern, Western and Southern Central Europe from South-eastern England to Crimea, Caucasus and Turkey, and is naturalised in North America (Conforti et al., 2012). This aromatical plant is effective as an antiseptic, antispasmodic and tonic. The essential oil of plant has antimicrobial, antifungal, antispasmodic, antioxidant and antitumor activities (Brankovic et al., 2009; Debbabi et al., 2020; Dzhambazov et al., 2002; Sarac \& Uğur, 2009; Tepe et al., 2007).

Microorganisms develop resistance to antibiotics due to the unconscious and inappropriate use of antibiotics resulting in the difficult treatment of infectious diseases. Especially, strains of Streptococcus sanguinis, Bacillus cereus, Escherichia coli, Pseudomonas aeruginosa, and Salmonella typhimurium are among the resistant pathogens to various antibiotics. P. aeruginosa is an ubiquitously distributed opportunistic Gramnegative pathogen that inhabits soil fresh water, marine environments, colonizing plant, animal, and human hosts. It is an opportunistic pathogen that is naturally resistant to many antibiotics. It is one of the causes of hospital infections (Goldberg and Pier, 2000). P. aeruginosa is responsible for ventilator-associated pneumonia, contact lens keratitis, otitis externa, cystic fibrosis (Wolska \& Szweda, 2009). Salmonella species are the most common causes of foodborne illness worldwide and $S$. typhimurium can cause infection in humans. It is a Gram-negative, facultative anaerobe bacterium and the leading cause of gastroenteritis 
(Patricia et al.,1986). E. coli is a Gram-negative, rod-shaped bacterium that is commonly found in the lower intestine of warm-blooded organisms. Most $E$. coli strains are harmless, but some serotypes can cause serious food poisoning in humans (Jang et al., 2017). S. sanguinis is an indigenous Gram-positive bacterium that has been recognized for a long time as a key player in colonization of the human oral cavity. $S$. sanguinis is considered a benign, or even a beneficial, bacterium with regard to dental caries (Kreth et al., 2005). $B$. cereus, Gram-positive, an ubiquitous organism, commonly found in soil, hay, live trees, and other plant material, raw and processed foods, post-operative wound infections, local infections with necrosis, intravenous drug abuse, alcoholism, osteomyelitis and trauma caused by B. cereus (Kotiranta et al. 2000). Diseases caused by multidrug resistant microorganisms can be treated by plant sources, especially with the antimicrobial activity of essential oils.

In this study, essential oil obtained from aerial parts of $C$. nepeta subsp. glandulosum was evaluated for its in vitro antibacterial properties against food and human pathogenic standard bacterial strains. Besides, the volatile components of the essential oil were also investigated.

\section{Materials and Methods}

\section{Materials}

Aerial parts of $C$. nepeta subsp. glandulosum were collected from Bilecik in July 2017, herbarium samples were prepared. Voucher specimens were deposited in the Herbarium of the Faculty of Pharmacy in Ankara University with the herbarium number of AEF 27033 and was air dried. The essential oil was isolated by hydrodistillation for $3 \mathrm{~h}$ using a Clevenger-type apparatus. Antibacterial activities of the $C$. nepeta subsp. glandulosum essential oil against Escherichia coli NRRL B-3008 (Agricultural Research Service Culture Collection), Bacillus cereus NRRL B-3711, Pseudomonas aeruginosa ATCC 27853 (American Type Culture Collection), Salmonella typhimurium ATCC 13311, and Streptococcus sanguinis ATCC 10556 strains were screened. Standard antibiotic ciprofloxacin and resazurin were acquired from Sigma-Aldrich.

\section{GC-FID and GC-MS analyses}

Gas Chromatography-Flame Ionization Detection (GC-FID) and Gas Chromatography-Mass Spectrometry (GCMS) analyses processes were performed with reference to Demirci et al. (2008).

\section{Identification of the components}

Identification of the essential oil components were carried out by comparison of their relative retention times with those of authentic samples or by comparison of their relative retention index (RRI) to series of $n$-alkanes. Computer matching against commercial (Wiley GC/MS Library, MassFinder Software 4.0) and in-house "Başer Library of Essential Oil Constituents" built up by genuine compounds and components of known oils.

\section{Antibacterial activity}

The antibacterial activity of the essential oil was evaluated by broth microdilution assay according to a modified Clinical and Laboratory Standards Institute (CLSI) method (CLSI, 2006). Escherichia coli NRRL B-3008, Bacillus cereus NRRL-B3711, Pseudomonas aeruginosa ATCC 27853, Salmonella typhimurium ATCC 13311, and Streptococcus sanguinis ATCC 10556 were used as test microorganisms. Minimal Inhibitory Concentrations (MIC) of the samples were determined and given in Table 2, where ciprofloxacin was used as a positive control in the experiments. The tests were carried out in 96 -well micro plates. The sample $(100 \mu \mathrm{L}$ per well) was diluted two-fold, with a final concentration range of 5000 to $9.76 \mu \mathrm{g} / \mathrm{mL}$, respectively. Standard antibacterial agent ciprofloxacin (64 to $0.125 \mu \mathrm{g} / \mathrm{mL}$ ) was used under the same conditions as positive 
controls. Strains were incubated in Mueller Hinton Broth (MHB) overnight at $37^{\circ} \mathrm{C}$ for $24 \mathrm{~h}$. Cultures, with a final inoculum size of $1 \times 10^{6}$ colonies forming units (CFU/mL) were used. Microbial growth was observed by adding $20 \mu \mathrm{L}$ of resazurin of $0.01 \%$ with minor modifications of CLSI standards (Pfaller et al., 2008). A change from blue to pink indicated the reduction of resazurin and, therefore, microbial growth. The minimal inhibitory concentration (MIC) was determined as the lowest drug concentration that prevented the colour change. All experiments were repeated in triplicate, and average results were reported.

\section{Results and Discussion}

\section{GC-FID and GC-MS analyses}

The greenish-yellow essential oil was analysed by GC-FID and GC-MS, simultaneously to determine its chemical characterization. Piperitenone oxide (47.8\%), limonene (18.6\%) and piperitone oxide II (13.6\%) were found as major components of the essential oil. Other components are given in Table 1.

Table 1. Volatile components of Clinopodium nepeta subsp. glandulosum essential oil

\begin{tabular}{|c|c|c|}
\hline aRRI & Component & $\%$ \\
\hline 1018 & Methyl-2-methyl butyrate & 0.1 \\
\hline 1032 & $\alpha$-Pinene & 1.0 \\
\hline 1035 & $\alpha$-Thujene & 0.1 \\
\hline 1063 & Ethyl-2-methyl butyrate & btr \\
\hline 1076 & Camphene & 0.1 \\
\hline 1118 & $\beta$-Pinene & 1.0 \\
\hline 1132 & Sabinene & 0.6 \\
\hline 1174 & Myrcene & 0.9 \\
\hline 1203 & Limonene & 18.6 \\
\hline 1213 & 1,8-Cineole & 0.4 \\
\hline 1246 & (Z)- $\beta$-Ocimene & $\operatorname{tr}$ \\
\hline 1255 & $\gamma$-Terpinene & $\operatorname{tr}$ \\
\hline 1280 & $p$-Cymene & $\operatorname{tr}$ \\
\hline 1393 & 3-Octanol & 1.3 \\
\hline 1474 & trans-Sabinene hydrate & 1.0 \\
\hline 1494 & (Z)-3-Hexyl-2-methyl butyrate & 0.1 \\
\hline 1497 & $\alpha$-Copaene & 0.1 \\
\hline 1535 & $\beta$-Bourbonene & 0.3 \\
\hline 1532 & Camphor & 0.2 \\
\hline 1553 & Linalool & 1.0 \\
\hline 1556 & cis-Sabinene hydrate & 0.2 \\
\hline 1571 & trans- $p$-Ment-2-en-1-ol & $\operatorname{tr}$ \\
\hline 1590 & Bornyl acetate & 0.2 \\
\hline 1612 & $\beta$-Caryophyllene & 0.9 \\
\hline 1611 & Terpinen-4-ol & 1.1 \\
\hline 1639 & trans-p-Mentha-2,8-dien-1-ol & 0.2 \\
\hline 1668 & (Z)- $\beta$-Farnesene & 0.2 \\
\hline 1678 & cis-p-Mentha-2,8-dien-1-ol & 0.1 \\
\hline 1706 & $\alpha$-Terpineol & 0.6 \\
\hline
\end{tabular}




\begin{tabular}{llc}
\hline 1719 & Borneol & 0.2 \\
1726 & Germacrene D & 0.6 \\
1733 & Piperitone oxide I & 0.3 \\
1755 & Piperitone oxide II & 13.6 \\
1751 & Carvone & 0.3 \\
1849 & Calamenene & 0.3 \\
1864 & $p$-Cymen-8-ol & 0.1 \\
1864 & Isopiperitonone & 0.6 \\
1880 & Benzyl-2-methyl-butyrate & 0.2 \\
1949 & Piperitenone & 0.6 \\
1983 & Piperitenone oxide & 47.8 \\
2006 & 8,9 -Dehydrothymol & 0.2 \\
2016 & $4 a \beta, 7 \alpha, 7 a \alpha$ Nepatalactone & 0.4 \\
2069 & $4 a \alpha, 7 \alpha, 7 a \beta$ Nepatalactone & 2.5 \\
2198 & Thymol & Tr \\
\hline & & 98.0 \\
\hline
\end{tabular}

aRRI: Relative retention indices calculated against $n$-alkanes, \%: calculated from FID data, btr: trace $<0.1 \%$

In a previous study of our group, forty-five components representing $91.65 \%$ of the oil were identified, piperitenone oxide (43.8\%), trans-piperitone oxide (25.2\%), and limonene (13.0\%) were found as the major components C. nepeta essential oil (Kirimer et al, 1992). Marongiu et al. (2010) were found pulegone, piperitenone oxide and piperitenone as the main components (64.4-39.9\%; 2.5-19.1\%; 6.4-7.7\%); conversely, the oil distilled from aerial parts of Portuguese $C$. nepeta is predominantly composed of isomenthone (35.8-51.3\%), 1,8-cineole (21.1-21.4\%) and trans-isopulegone (7.8-6.0\%) (Marongiu et al., 2010). Another study reported that, pulegone (40.5-54\%) and menthone (23.6-16\%) were found as the main components C. nepeta essential oil, respectively (Şarer \& Pançalı, 1998; Demirci et al. 2011). Kitic et al. (2002) determined that pulegone $(37.5 \%)$, menthone $(17,6 \%)$, piperitenone $(15.0 \%)$ and piperitone were as the main constituents in the oil (Kitic et al., 2002).

\section{Antibacterial activity}

The potential in vitro antibacterial activity of the essential oil was tested against Escherichia coli NRRLB-3008, Pseudomonas aeruginosa ATCC 27853, Salmonella typhimurium ATCC 13311, Bacillus cereus NRRL-B3711 and Streptococcus sanguinis ATCC 10556 were used by broth microdilution method. Ciprofloxacin was used as control and Minimal Inhibitory Concentrations (MIC) were determined. The essential oil is more effective against $B$. cereus $(2500 \mu \mathrm{g} / \mathrm{mL}), S$. sanguinis $(2500 \mu \mathrm{g} / \mathrm{mL})$ and $S$. typhimurium $(1250 \mu \mathrm{g} / \mathrm{mL})$. The lowest activities were determined against $E$. coli $(5000 \mu \mathrm{g} / \mathrm{mL})$ and $P$. aeruginosa $(10000 \mu \mathrm{g} / \mathrm{mL})$. The results were given in Table 2.

Table 2. Minimal inhibitory concentration values (MIC) $(\mu \mathrm{g} / \mathrm{mL})$

\begin{tabular}{lcc}
\hline Bacteria & $\begin{array}{c}\text { C. nepeta subsp. glandulosum } \\
\text { essential oil }\end{array}$ & Ciprofloxacin \\
\hline Escherichia coli NRRLB-3008 & 5000 & 30 \\
Pseudomonas aeruginosa ATCC 27853 & 10000 & 30 \\
Salmonella typhimurium ATCC 13311 & 1250 & 30 \\
Bacillus cereus NRRL-B3711 & 2500 & $<10$ \\
Streptococcus sanguinis ATCC 10556 & 2500 & $<10$ \\
\hline
\end{tabular}


Numerous studies exist on the $C$. nepeta essential oil antibacterial activity, where varying amounts of the tested pathogens were found to be susceptible to the oil were reported (Arantes et al., 2019; Miladinovic et al., 2012; Kitic et al., 2002). In previous study, MIC values of $C$. nepeta essential oil were determined against S. aureus $(>2.0 \mu \mathrm{L} / \mathrm{mL})$, E. coli $(1.0 \mu \mathrm{L} / \mathrm{mL})$, S. typhimurium $(>2.0 \mu \mathrm{L} / \mathrm{mL})$ and P. aeruginosa $(1.0 \mu \mathrm{L} / \mathrm{mL})$ (Arantes et al., 2019). According to other study, essential oil from C. nepeta have antimicrobial activity with a range of MIC values from 0.025 to $1.56 \mu \mathrm{L} / \mathrm{mL}$ (Miladinovic et al., 2012). In another study, antimicrobial activity of $C$. nepeta essential oil was determined by disk diffusion method. All tested microorganisms were found to be susceptible to essential oil (Kitic et al., 2002).

\section{Conclusion}

In the present study, piperitenone oxide (47.8\%), limonene (18.6\%) and piperitone oxide II (13.6\%) were found as major components of the essential oil. Also, the essential oil of $C$. nepeta subsp. glandulosum showed different levels of activities against E. coli, P. aeruginosa, S. typhimurium, B. cereus and S. sanguinis. It was shown more effective against B. cereus $(2500 \mu \mathrm{g} / \mathrm{mL})$, S. sanguinis $(2500 \mu \mathrm{g} / \mathrm{mL})$ and S. typhimurium $(1250 \mu \mathrm{g} / \mathrm{mL})$. The lowest activities were determined against $E$. coli $(5000 \mu \mathrm{g} / \mathrm{mL})$ and $P$. aeruginosa $(10000$ $\mu \mathrm{g} / \mathrm{mL}$ ). More in detail evaluations on biological activity both on in vitro and in vivo levels are needed to exhaust the potential of essential oil from $C$. nepeta. Further work is ongoing.

\section{ACKNOWLEDGMENT}

This work was presented at the WOCMAP 2019 - 6th World Congress on Medicinal and Aromatic Plants, Famagusta, N. Cyprus.

\section{CONFLICTS OF INTEREST}

The authors have no conflicts of interest to declare.

\section{REFERENCES}

Arantes, S. M., Piçarra, A., Guerreiro, M., Salvador, C., Candeias, F., Caldeira, A. T., \& Martins, M. R. (2019). Toxicological and pharmacological properties of essential oils of Calamintha nepeta, Origanum virens and Thymus mastichina of Alentejo (Portugal), Food and Chemical Toxicology, 133, 110747.

Baytop, T. (1999). Therapy with Medicinal Plants in Turkey. Istanbul: Nobel Tıp Basımevi.

Brankovic, S. V., Kitic, D. V., Radenkovic, M. M., Veljkovic, S. M., \& Golubovic, T. D. (2009). Calcium blocking activity as a mechanism of the spasmolytic effect of the essential oil of Calamintha glandulosa Silic on the isolated rat ileum. General Physiology and Biophysics, 28, 174-178.

Conforti, F., Marrelli, M., Statti, G., Menichini, F., Uzunov, D., Solimene, U., \& Menichini, F. (2012). Comparative chemical composition and antioxidant activity of Calamintha nepeta (L.) Savi subsp. glandulosa (Req.) Nyman and Calamintha grandiflora (L.) Moench (Labiatae), Natural Product Research, 26(1), 91-97.

Davis, P.H. (1982). Flora of Turkey and East Aegean Islands. Edinburg: University Press

Debbabi, H., Mokni, R. E., Chaieb, I., Nardoni, S., Maggi, F., Caprioli, G., \& Hammami, S. (2020). Chemical Composition, Antifungal and Insecticidal Activities of the Essential Oils from Tunisian Clinopodium nepeta subsp. nepeta and Clinopodium nepeta subsp. glandulosum. Molecules, 25(9), 2137.

Demirci, B., Temel, H. E., Portakal, T., Kırmızıbekmez, H., Demirci, F., \& Başer, K. H. C., (2011). Inhibitory effect of Calamintha nepeta subsp glandulosa essential oil on lipoxygenase. Turkish Journal of Biochemistry, 36(4), 290-295.

Demirci, F., Güven, K., Demirci, B., Dadandı, M. Y. \& Baser, K. H. C. (2008). Antibacterial activity of two Phlomis essential oils against food pathogens. Food Control, 19(12), 1159-1164. 
Dzhambazov, B., Daskalova, S., Monteva, A., \& Popov, N. (2002). In vitro screening for antitumour activity of Clinopodium vulgare L. (Lamiaceae) extracts. Biological and Pharmaceutical Bulletin, 25(4), 499-504.

Govaerts R. (1999). World checklist seed plants 3. Continental Publishing, Deurne.

Jang, J., Hur, H.G., Sadowsky, M.J., Byappanahalli, M.N., Yan, T., \& Ishii, S. (2017). Environmental Escherichia coli: ecology and public healthimplications-a review, Journal of Apply Microbiology, 123, 570-581.

Kirimer, N., Baser, K. H. C., Özek, T., \& Kürkçüoğlu, M. (1992). Composition of the essential oil of Calamintha nepeta subsp. glandulosa, Journal of Essential Oil Research, 4, 189-190.

Kitic, D., Jovanovic, T., Ristic, M., Palic, R., \& Stojanovic, G. (2002). Chemical composition and antimicrobial activity of the essential oil of Calamintha nepeta (L.) Savi ssp. glandulosa (Req.) P. W. Ball from Montenegro, Journal of Essential Oil Research, 14, 150-152.

Kotiranta, A., Lounatmaa, K., \& Haapasalo, M. (2000). Epidemiology and pathogenesis of Bacillus cereus infections. Microbes and Infection, 2(2), 189-198.

Kreth, J., Merritt, J., Shi, W., \& Qi, F. (2005). Competition and coexistence between Streptococcus mutans and Streptococcus sanguinis in the dental biofilm. Journal of Bacteriology, 187(21), 7193-7203.

Marongiua, B., Piras, A., Porcedda, S., Falconieri, D., Maxia, A., Gonçalves, M. J., Cavaleiro, C., \& Salgueiro, L. (2010). Chemical composition and biological assays of essential oils of Calamintha nepeta (L.) Savi subsp. nepeta (Lamiaceae), Natural Product Research, 24(18), 1734-1742.

Miladinović, D. L., Ilić, B. S., Mihajilov-Krstev, T. M., Nikolic, N. D., Miladinovic, L. C., \& Cvetkovic, O. G. (2021) Investigation of the chemical composition-antibacterial activity relationship of essential oils by chemometric methods. Analytical and Bioanalytical Chemistry, 403, 1007-1018.

Patricia, I. F., Ronald, S., Constantine, H., \& Fred, H. (1986). Mutants of Salmonella typhimurium that cannot survive within the macrophage are a virulent. Proceedings of the National Academy of Sciences of the United States of America, 83, 5189-5193.

Pfaller, M. A., Chaturvedi, V., Diekema, D. J., Ghannoum, M. A., Holliday, N. M., Killian, S. B., Knapp C. C., Messer, S. A., Miskov. A., \& Ramani, R. (2008). Clinical evaluation of the Sensititre YeastOne colorimetric antifungal panel for antifungal susceptibility testing of the echinocandins anidulafungin, caspofungin, and micafungin. Journal of Clinical Microbiology, 46(7), 2155-2159.

Sarac, N., \& Ugur, A. (2009). The in vitro antimicrobial activities of the essential oils of some Lamiaceae species from Turkey. Journal of Medicinal Food, 12(4), 902-907.

Şarer, E., \& Pançalı, S. S. (1998). Composition of the Essential Oil from Calamintha nepeta (L.) Savi ssp. glandulosa (Req.) P. W. Ball, Flavour and Fragrance Journal, 13, 31-32.

Tepe, B., Sihoglu-Tepe, A., Daferera, D., Polissiou, M., \& Sokmen, A. (2007). Chemical composition and antioxidant activity of the essential oil of Clinopodium vulgare L. Food Chemistry, 103(3), 766-770.

Wolska, K., \& Szweda, P. (2009). Genetic Features of Clinical Pseudomonas aeruginosa Strains. Polish Journal of Microbiology, 58(3), 255-260. 